Editorial

\title{
EES and the continuing evolution of Research Policy
}

\section{Introduction}

Research Policy (RP) continues to grow and flourish. The journal receives increasing numbers of submissions from all round the world, with the growth being particularly rapid outside of North America and Western Europe. In 2008, the ten issues totalled nearly 2000 pages and included 125 full-length research articles. The articles published are highly regarded and have a significant impact, as reflected in the journal's impact factor (JIF), which rose appreciably last year. Because of the growing scale and complexity of the business involved in reviewing and editing all the submitted papers, the journal has now switched to using Elsevier's Electronic Editorial System (EES). This handles the on-line submission of papers as well as the reviewing and editing process. The switch took place at the beginning of 2009 , although there had been a pilot scheme operating over the previous six months to sort out teething problems. This Editorial explains the background to that move, setting it in the context of the evolving strategy for the journal. There are also several other important issues that have arisen over the last year or two and which the Editors would like to bring to the attention of readers. $^{3}$

\section{Overall strategy, including the positioning of Research Policy}

The broad strategy pursued by the Editors is to position RP at the intersection of cognate social science disciplines (in particular, economics, management, policy studies and political science, organisational science, sociology, and history of technology and innovation). ${ }^{4}$ We look for papers that deal with 'heartland' RP issues such as innovation, technology, R\&D, science and so on, ${ }^{5}$ and which are likely to be of interest to the 'broad church' of RP readers coming from these various cognate disciplines.

One consequence of RP's success in achieving a high impact factor (see Section 6 below) is that we are attracting more papers from economics departments and business schools. In both these cases,

\footnotetext{
${ }^{3}$ Alert readers (at least of the printed version of Research Policy) may also have spotted a number of changes to the format over the last year, including the adoption of a simpler 'cleaner' cover and a switch to a slightly larger page size (the latter being to bring the journal into line with the Elsevier standard as well as to save paper and thus keep the environmental 'footprint' of RP to a minimum).

4 'Maps' based on co-citation patterns among journals (and supplied to the Editors by Elsevier) suggest that we have managed to do this quite successfully in recent years.

5 See the more detailed list of key words on the RP website at http://www.elsevier. com/wps/find/journaldescription.cws_home/505598/description.
}

a growing number of leading researchers seem to be focussing on innovation and technology, and on related issues such as entrepreneurship. However, some of the papers that we receive from these sources have little direct relationship to 'heartland' RP issues; even if such papers are good, they are likely to be rejected as 'out of scope'. In addition, some submissions, while they address an RP issue, may do so in a manner that is more appropriate to publication in a mainstream economics or management journal. Authors intending to submit to RP need to ensure that not only is the theme of the paper one that is covered by RP, but also that they approach the topic in a manner that is likely to be of interest to a large proportion of RP readers (i.e. it is neither too narrow nor too technical). Amongst other things, this includes engaging substantially with the body of literature familiar to the journal's readership as well as focusing on research with potentially important policy or management implications.

\section{Adoption of EES}

The switch to Elsevier's Electronic Editorial System (EES) took place at the start of 2009. All authors submitting an article are now requested to go to the EES website at http://ees.elsevier. $\mathrm{com} / \mathrm{respol} /$, where they will find instructions about the submission process, in particular the need to submit an anonymised version as well as one with full details of the authors. ${ }^{6}$ (Referees asked to review a paper by an RP Editor will also be directed to the EES site and provided with a password for carrying out this task.) As before, authors submitting a paper first need to identify which of the RP authors is best suited to act as Editor in the light of the content of the paper, ${ }^{7}$ and the EES system will prompt them about this. To help with this, we will make available on the RP website a list of key words characterising the areas of expertise of each of the RP Editors.

As scholars of the innovation process, we are all too mindful of the problems that can beset the introduction of an innovation such as EES. Consequently, we have been conducting a pilot exercise over the previous six months, in which two of the RP Editorial Offices have been asking authors of new articles to submit them via the EES website. This has enabled us to test Elsevier's EES configuration for RP (with its particular organisational structure and review procedures) and to sort out any teething problems. In particular, we

\footnotetext{
6 All articles submitted to RP are now subject to a full 'double blind' review process. 7 However, authors should not submit to an RP Editor from the same institution where they are employed (or have been employed over the last five years), nor to an Editor with whom they worked over the last five years.
} 
have been working to ensure that there is sufficient flexibility in the system to ensure that fully customised email letters can be produced, thereby retaining the more personal touch of the previous 'manual' system. Thus far, over 150 articles have been entered into EES, with some having already reached the final step of acceptance or rejection, and the system appears to be working reasonably well. Indeed, there is some preliminary evidence that it may on average slightly speed up the response from referees, an issue to which we turn next.

\section{Speed of turnaround for RP papers}

Analysis of the time from initial submission to acceptance shows that the average acceptance time has been increasing over previous years. The main delays come from the following sources:

1. difficulties in finding referees willing to accept the task-this is unfortunately a growing problem; many researchers are claiming they are "too busy" or that it is "not their subject"; and regrettably some leading academics apparently believe that it is no longer their responsibility to make such 'public good' contributions $^{8}$; they feel they are "too posh to peer review", 9 as one RP Editor put it;

2. slow response from referees-some can take several months, despite repeated promises and deadlines; this appears to be linked to a widespread sense among researchers of being increasingly overloaded, with email communication no longer necessarily receiving prompt attention;

3. authors may be slow to make the changes requested by referees before resubmitting-however, this is more an issue for authors than for the journal;

4. referees may require a second substantial revision of the paper before finally recommending acceptance; this is particularly likely to occur if the authors have been too perfunctory in their response to the first set of criticisms and recommendations by the referees;

5. Editors, faced with the growing workload, may be slow in handling the various stages of the review and editing process; in particular, the growing volume of submitted papers includes a significant proportion that are either 'out of scope' or 'not good enough to send to referees', so a considerable amount of time must be devoted by Editors to reading them and deciding which should be rejected at this initial stage (i.e. 'desk rejection'). ${ }^{10}$

Full-scale implementation of EES will enable us to keep closer track of referees (which individuals have already done 'their share' of reviewing in the last few months, who habitually turns us down, who is perennially late, who writes cursory or bland reviews, who is overly critical, and so on). This should enable Editors to make betterinformed choices in the future with regard to referees, and thereby ensure a speedier and more effective outcome for individual papers. EES will also provide RP Editors with a constantly updated personal 'to do' list, making it easier to keep up to date with our respective assignments than in the old system (part paper-based files, part emails and attachments).

\footnotetext{
${ }^{8}$ As Kirby (2005) has wryly noted, "it is ... not hard to devise a game theory situation in which the most successful academics expect to be able to publish but refuse to waste their time in doing refereeing - thus increasing the likelihood of their further success".

9 The growing numbers of celebrity mothers opting for Caesarean deliveries have been labelled as "too posh to push" in popular British newspapers.

10 The aim of such 'desk rejection' is to avoid overburdening reviewers with papers that have virtually no chance of being accepted, and also to provide the authors of such papers with a prompt response so that they can then try another journal. The advice of an Advisory Editor closer to the topic is often sought in such cases.
}

However, all these improvements hinge on researchers (including the most eminent ones, who themselves undoubtedly benefited from peer review when they were relatively junior) continuing to recognise that carrying out the peer review of submitted articles is a civic duty incumbent on all of us (Kirby, 2008). If the number abrogating themselves of this responsibility grows, it adds to the burden of those who remain willing to carry out peer review, and runs the risk of creating a new form of 'the tragedy of the commons'. ${ }^{11}$

\section{Special Issues}

$\mathrm{RP}$ has also been receiving a growing number of proposals for Special Issues, perhaps because these are often now seen as an appropriate end product of a major collaborative project or a conference. Special Issues can undoubtedly fulfil a number of important purposes. These include:

- bringing together and integrating work on a specific theme (for instance, bringing together theoretical and empirical work, or work based on different methodological approaches);

- opening up a previously under-researched area (or one that has perhaps struggled with a rather conservative peer review process in its efforts to achieve recognition);

- constructing a bridge between formerly rather separate research communities, who have been focussing on similar or related topics.

Nevertheless, we must beware the danger of publishing 'too many' Special Issues for the tastes of our readers. The strategy agreed by RP Editors is that, out of the total of ten issues published each year, only two should be Special Issues (although there may occasionally also be a smaller 'Special Section', with the remainder of that issue consisting of 'normal' articles).

Faced with a dozen or more Special Issue proposals each year, we have instituted a more formal procedure for deciding which of these should be accepted. Proposals are considered twice a year (in January and July). Those thinking of submitting a proposal should first obtain a copy of the 'Notes for Proposers and Guest Editors' from the web or from respol@sussex.ac.uk. This provides guidance on the nature and content of the 2-4 page proposal required. Proposals should be submitted to respol@sussex.ac.uk at the start of January or July. These are then reviewed by the RP Editors on the basis of certain criteria that include: the novelty, importance and topicality of the theme; whether the papers will form an integrated whole; the standing of the authors; the experience of the Guest Editors in handling a task of this magnitude; and the overall 'added value' of a Special Issue (as compared with publishing these papers separately in 'normal' issues). Those thinking of submitting a proposal, however, should bear in mind that, out of the half a dozen or so proposals considered every six months, only one on average will be allocated a Special Issue 'slot', so the competition is extremely tough. A clutch of loosely connected papers from a conference on a fairly standard subject is unlikely to be accepted.

\footnotetext{
11 Ernst Fehr (an economist who is an expert on the lessons from game-playing with respect to cooperation and altruism, and in particular the need for punishment mechanisms to deter 'defectors' or 'free-loaders'), and Marc Hauser (a psychologist and evolutionary biologist who, amongst other things, has worked on the nature of moral judgements) have put forward a somewhat provocative proposal for encouraging reviewers to respond promptly; namely, that those referees who are late are penalised by a delay of twice that length when they next submit a paper for review (see Hauser and Fehr, 2007). One hopes that such sanctions never prove necessary!
} 
Table 1

Impact Factor of leading Management journals.

\begin{tabular}{|c|c|c|c|c|c|c|}
\hline Rank & Abbreviated journal Title & Total cites & Impact factor & Immediacy index & Articles & Cited half-life \\
\hline 1 & MIS Quart & 4329 & 5.83 & 0.53 & 30 & 9.4 \\
\hline 2 & Acad Manage J & 9555 & 5.02 & 2.23 & 65 & $>10.0$ \\
\hline 3 & Acad Manage Rev & 8341 & 4.37 & 1.09 & 55 & $>10.0$ \\
\hline 4 & Organ Sci & 5137 & 3.13 & 0.67 & 58 & 9.2 \\
\hline 5 & Admin Sci Quart & 7123 & 2.91 & 0.50 & 12 & $>10.0$ \\
\hline 6 & Strategic Manage J & 9512 & 2.83 & 0.44 & 68 & $>10.0$ \\
\hline 7 & Acad Manag Learn Edu & 338 & 2.80 & 0.75 & 20 & 3.3 \\
\hline 8 & Inform Syst Res & 2146 & 2.68 & 0.13 & 23 & 8.3 \\
\hline 9 & Organ Res Methods & 615 & 2.55 & 0.27 & 30 & 6.2 \\
\hline 10 & J Int Bus Stud & 3101 & 2.28 & 0.35 & 66 & $>10.0$ \\
\hline 11 & Res Policy & 3524 & 2.21 & 0.44 & 100 & 6.8 \\
\hline 12 & Organ Stud & 1719 & 2.04 & 0.58 & 84 & 6.9 \\
\hline 13 & J Manage & 3755 & 2.00 & 0.32 & 37 & $>10.0$ \\
\hline 14 & J Organ Behav & 2494 & 1.98 & 0.26 & 47 & 8.1 \\
\hline 15 & Manage Sci & 12110 & 1.93 & 0.26 & 133 & $>10.0$ \\
\hline 16 & J Manage Stud & 2279 & 1.93 & 0.70 & 69 & 7.3 \\
\hline 17 & J Manage Inform Syst & 1861 & 1.87 & 0.18 & 40 & 7.7 \\
\hline 18 & J Oper Manag & 1971 & 1.85 & 0.49 & 82 & 7.3 \\
\hline 19 & Organ Behav Hum Dec & 4402 & 1.85 & 0.45 & 49 & $>10.0$ \\
\hline 20 & Leadership Quart & 1059 & 1.76 & 0.34 & 35 & 6.6 \\
\hline
\end{tabular}

Source: Thomson Reuters, JCR Social Science Edition, 2007. MIS, Management Information Systems.

Table 2

Impact Factor of leading Economics journals.

\begin{tabular}{|c|c|c|c|c|c|c|}
\hline Rank & Abbreviated journal title & Total cites & Impact factor & Immediacy index & Articles & Cited half-life \\
\hline 1 & J Polit Econ & 10878 & 4.19 & 0.89 & 27 & $>10.0$ \\
\hline 2 & J Econ Lit & 3201 & 3.97 & 0.67 & 18 & 9.8 \\
\hline 3 & QJ Econ & 8713 & 3.69 & 0.77 & 44 & $>10.0$ \\
\hline 4 & J Account Econ & 1784 & 3.03 & 0.41 & 34 & 9.0 \\
\hline 5 & J Financ Econ & 6980 & 2.99 & 0.57 & 103 & $>10.0$ \\
\hline 6 & Econometrica & 13864 & 2.97 & 0.43 & 51 & $>10.0$ \\
\hline 7 & J Econ Perspect & 3319 & 2.83 & 0.33 & 45 & 9.5 \\
\hline 8 & J Econ Geogr & 571 & 2.68 & 0.93 & 30 & 4.0 \\
\hline 9 & Rev Econ Stud & 4648 & 2.54 & 0.51 & 47 & $>10.0$ \\
\hline 10 & J Econ Growth & 690 & 2.29 & 0.58 & 12 & 6.9 \\
\hline 11 & Am Econ Rev & 16642 & 2.24 & 0.29 & 184 & $>10.0$ \\
\hline 12 & Res Policy & 3524 & 2.21 & 0.44 & 100 & 6.8 \\
\hline 13 & Econ Geogr & 768 & 2.07 & 0.47 & 15 & 9.8 \\
\hline 14 & J Econometrics & 5288 & 1.99 & 0.27 & 176 & $>10.0$ \\
\hline 15 & J Policy Anal Manag & 739 & 1.80 & 0.35 & 34 & 6.3 \\
\hline 16 & Rev Econ Stat & 4714 & 1.72 & 0.40 & 58 & $>10.0$ \\
\hline 17 & World Bank Res Obser & 363 & 1.70 & 0.00 & 10 & 7.9 \\
\hline 18 & Econ Soc & 901 & 1.68 & 0.18 & 28 & 8.0 \\
\hline 19 & Health Econ & 1835 & 1.65 & 0.26 & 85 & 5.8 \\
\hline 20 & J Law Econ & 1982 & 1.62 & 0.71 & 14 & $>10.0$ \\
\hline 21 & Energ J & 736 & 1.58 & 0.27 & 30 & 7.8 \\
\hline
\end{tabular}

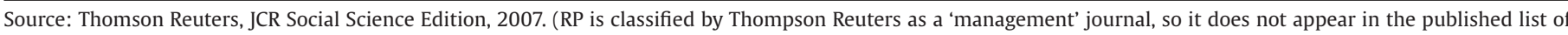
economics journals. It has been inserted in the table here to show how it compares with leading economics journals.)

\section{Journal impact factor (JIF)}

Each year, Thomson Reuters (the owners of the former Institute for Scientific Information) publishes data on the 'impact factors' of the several thousand journals included in the Citation Index. The JIF for each journal is calculated by taking the total number of citations in the latest year to all forms of publication appearing in that journal over the previous two years, divided by the total number of articles published by the journal over that two-year period. As a measure of a journal's research standing, this indicator has well known limitations. In particular, not all sources of citations are scanned (books, book chapters, conference proceedings, more nationally or regionally oriented journals particularly those from outside North America and Western Europe, and most non-English language publications are excluded from the items scanned by the Citation Index). This means that publications in the social sciences (and even more so the humanities) tend to 'lose' a significant proportion of their potential citations. ${ }^{12}$ In addition, in social sciences and humanities it generally takes considerably more than two years for articles to achieve their peak rate of citations. Impact factors for social science journals therefore tend to be rather low and to exhibit a significant degree of volatility from one year to the next (i.e. the data are 'noisy'). Yet despite these limitations, JIF data are increasingly used for comparing journals and for other research assessment purposes around the world.

The latest figures (for 2007) show that RP now has a JIF of 2.21, a major improvement over previous years. In the list of the world's leading management journals (see Table 1), this places us 11th, a highly commendable result. Likewise, if RP is compared with the top economics journals (see Table 2), the JIF score of 2.21 would

\footnotetext{
12 This is somewhat less of a problem for economics than for most other social
} sciences. 
put us in the equivalent of 12th position, just behind American Economic Review, an outstanding result given the much greater size of the economics community (and hence the far bigger population of potential citers) compared with the RP community. Moreover, all this has been achieved without resort to any of the stratagems of 'citation engineering' that certain other journals may have adopted in order to artificially inflate their JIF. ${ }^{13}$

\section{Avoiding research misconduct}

Evidence over the last 10 years suggests there has, alas, been a growing problem in the wider academic community with issues relating to research conduct. These range from slightly dubious publication practices through to more blatant examples of plagiarism and other forms of research misconduct. Examples encountered by RP Editors over the last year or so include the following:

1. 'Salami publishing'-authors (perhaps under pressure to maximise their published output) write two papers drawing on the same study but analysing the data in slightly different ways and then submit these separately to the same journal but different Editors, not divulging the existence of each paper in the other.

2. Self-plagiarism-the content of a paper submitted to RP is very similar to that in an earlier publication by the same authors in another journal, with the authors again failing to acknowledge that other publication.

3. Strings of words or even entire sentences are virtually identical to those in an earlier publication by someone else-the author cites that earlier document but then fails either to put identical text in inverted commas, or to completely rewrite in his/her own words. As we stress to our students, this, too, can be construed as plagiarism; they must choose one or other of these two alternatives-there is no 'third way'.

4. The author takes whole paragraphs or sections of text from a previous publication, just changing a few words, and then presents this as his ${ }^{14}$ own work, with no citation to the original source. This is outright plagiarism (see Martin et al., 2007).

The RP Editors have begun to compile a central register of the examples encountered and how each has been dealt with, so that we have clear case precedents on which future actions can be based. In general, if there are signs of an intent to deceive on the part of the author (e.g. not disclosing the existence of a closely related paper by the author, or failing to cite the source of material included in the text), this may be taken to imply a degree of premeditation, in which case the matter will be treated far more seriously. In less serious cases, authors will be given a (single) chance to rectify the problem. In more serious cases, the paper will be rejected. Moreover, if the research misconduct is particularly flagrant, the author's superiors (e.g. the head of department) may be informed as well so that they can investigate the matter more thoroughly. ${ }^{15}$

Authors are reminded that, when submitting a paper, they are required to provide a confirmation that this work has not previously

\footnotetext{
13 These include: (i) publishing large numbers of Editorials, notes, letters to the Editor, book reviews etc., all of which may earn citations that contribute to the overall citation total, but which do not 'count' in the denominator in the JIF calculation; (ii) informing submitting authors that they expect them to cite a certain minimum number of articles from their journal; and (iii) publishing Editorials that cite large numbers of articles in the journal from the last two years.

14 The great majority of known examples of plagiarism and other serious research misconduct in recent years seem to have involved male rather than female researchers.

${ }^{15}$ One of the Editors (Ben Martin) is also a member of the Committee on Publication Ethics (COPE), a body consisting of Editors of leading journals, and this provides another avenue by which more serious cases can be pursued.
}

been published. If they are in the slightest doubt (in particular, they may be unclear as to what constitutes prior 'publication' ${ }^{16}$ ), they should specifically check with the RP Editor as to whether their paper meets this criterion or not. The RP Editor involved will then provide a ruling, or alternatively ask referees to judge whether the new paper makes sufficient of a new contribution compared with the previous paper(s) to merit publication in RP. Referees are likewise reminded that, if they have reasonable suspicions about the integrity of an article (and EES includes access to SCOPUS ${ }^{17}$, which should make checking on such matters rather easier), then they should draw this explicitly to the attention of the Editor involved.

\section{Changes to the Advisory Editors and to the Editors}

If RP is to continue to thrive, there need to be periodic changes to the Advisory Editors and the Editors, bringing on board those with the talent and the dedication required for these important roles. The Advisory Board was substantially changed two years ago, with the appointment of 30 new Advisory Editors. It is the intention to re-examine this in a year's time. Those individuals who believe they have the necessary experience and enthusiasm to be considered for this role should raise this with one of the Editors during 2009.

In addition, over the next couple of years, four or five of the current nine RP Editors may be stepping down or retiring. In the past, RP has tended to replace Editors one by one, often on a 'likefor-like' basis. However, with so many about to be replaced at more or less the same time, there is a unique opportunity to take a more systematic look at current Editors, their areas of competence, and the 'gaps' that we should attempt to fill in making the replacements. Among those gaps are likely to be:

- economics of innovation/technology

- organisational studies of innovation/technology etc.

- technology and development, innovation in developing, transitional and 'catch up' countries

- innovation/technology in Asia and other regions, including Eastern Europe, Latin America and Africa

Over the next six months, the RP Editors and Advisory Editors will be considering this matter so, if you have any suggestions, you should again discuss this with one of them.

\section{Conclusion}

All the evidence available suggests that Research Policy is in robust health. It attracts growing numbers of submissions. Published articles attract much attention and have a considerable impact, as reflected in a JIF value that compares extremely favourably with the world's leading management and economics journals. For this, we should thank all who have contributed-authors, reviewers, Advisory Editors and our publishers, Elsevier. The switch to the Electronic Editorial System (EES) should enable us to continue to handle the growing volume of business in an efficient and expeditious manner.

Even so, we will continue to need the help of all of you. To limit the burden on Editors, authors thinking of submitting to RP for the first time should familiarise themselves with the scope of the journal, the type of approach that is likely to be of interest to the 'broad

\footnotetext{
${ }^{16}$ For example, if an earlier conference version of the paper is available on a website or distributed on a CD, does this constitute 'publication'? In such cases, the author should ask the RP Editor for a ruling.

17 SCOPUS is a relatively new database set up by Elsevier. It contains publication and citation data for articles published since 1996 from 16,000 peer-reviewed journals in the sciences and social sciences.
} 
church' of RP readers, and the body of literature that researchers in the field orient themselves to, as well as ensuring that the research they are reporting yields some clear and specific policy or management implications. Those selected as reviewers need to continue to view this task as an important contribution to the common good, a responsibility that should therefore be accorded the necessary priority in their ever-lengthening 'to do list' to ensure that they complete it in a timely fashion. Advisory Editors, besides acting as referees and as advisers as to whether submitted papers are 'within scope' and 'good enough to send to referees', should continue to serve as 'ambassadors' for the journal, seeking to encourage and attract good papers from up-and-coming as well as established researchers all round the world. Finally, within the next year, we shall need a number of volunteers to step forward and assume the role of Advisory Editors and Editors. With all of this, the continuing success of Research Policy over coming years should be assured for some time to come, and, with it, its reputation as the leading journal in the area.

\section{References}

Hauser, M., Fehr, E., 2007. An incentive solution to the peer review problem. PLOS Biology 5 (April (4)), 0703 (accessed 10.02.09) http://biology. plosjournals.org/archive/1545-7885/5/4/pdf/10.1371_journal.pbio.0050107L.pdf.

Kirby, A., 2005. Peering into the future of academic review. Cities 22, 85-87.
Kirby, A. S, 2008. Peer review: towards better practices, presentation at the Elsevier Editors' Conference, Nice, 8 November.

Martin, B.R., et al., 2007. Keeping plagiarism at bay-a salutary tale. Research Policy 36, 905-911.

Ben R. Martin*,2

Martin Bell ${ }^{2}$

Michel Callon ${ }^{2}$

Hariolf Grupp ${ }^{1,2}$

Fumio Kodama ${ }^{2}$

Stefan Kuhlmann ${ }^{2}$

Lee Fleming ${ }^{2}$

Nick von Tunzelmann ${ }^{2}$

Walter Powell ${ }^{2}$

SPRU-Science and Technology Policy Research, The Freeman Centre, University of Sussex, Brighton BN1 9QE, UK

* Corresponding author. Tel.: +44 1273 873562;

fax: +441273685865.

E-mail address: B.Martin@sussex.ac.uk (B.R. Martin)

${ }^{1}$ Deceased.

2 The Editors of Research Policy.

Available online 25 March 2009 